\title{
Type 2-diabetes og metabolsk syndrom før og etter gastrisk bypass
}

\begin{abstract}
Sammendrag
Bakgrunn. Overvekt og fedme disponerer for utvikling av type 2-diabetes og metabolsk syndrom. Vi har undersøkt forekomsten av disse tilstandene $f ø r$ og etter gastrisk bypass-operasjon for sykelig fedme.
\end{abstract}

Materiale og metode. Pasienter operert med laparoskopisk gastrisk bypass ved Oslo universitetssykehus, Aker i perioden 1.1. 2007 til 31.12. 2007, med oppfølgingsdata mer enn seks måneder etter operasjonen, ble inkludert. Type 2-diabetes ble definert som tilstedeværelse av minst ett av følgende kriterier: etablert diagnose før operasjon, fastende plasma-glukose $\geq 7,0 \mathrm{mmol} / \mathrm{l}$ eller $\mathrm{HbA}_{1 \mathrm{c}} \geq 6,5 \%$. For metabolsk syndrom ble kriteriene fra National Cholesterol Education Program benyttet.

Resultater. Totalt 136 pasienter ble inkludert. Alderen var $43 \pm 9$ år (gjennomsnitt \pm standardavvik) og $79 \%$ var kvinner. Gjennomsnittlig oppfølgingstid var 17 måneder (spredning 8-26 md.). Pasientenes kroppsmasseindeks (BMI kg/m²) ble redusert fra $47 \pm 6$ før operasjon til $32 \pm 6$ etter $(p<0,001)$. Andel pasienter med type 2 -diabetes var $34 \%$ før operasjon og $10 \%$ etter ( $p<0,001)$. Tilsvarende tall for metabolsk syndrom var henholdsvis $80 \%$ og $24 \%$ ( $p<0,001)$. Gjennomsnittlige eller mediane verdier for fastende plasmaglukose, $\mathrm{HbA}_{1 c}$ og alle variabler som inngår i definisjonen av metabolsk syndrom ble statistisk signifikant bedret hos pasienter med disse diagnosene.

Fortolkning. Gastrisk bypass har en gunstig effekt på type 2-diabetes. Blodsukkernivået ble normalisert hos de fleste pasientene etter operasjon. Behandlingen førte også til statistisk signifikant lavere forekomst av metabolsk syndrom.

\author{
Torgeir T. Søvik \\ t.t.sovik@medisin.uio.no \\ Senter for sykelig overvekt \\ og \\ Gastroenterologisk kirurgisk avdeling \\ Oslo universitetssykehus, Aker \\ 0514 Oslo \\ og \\ Det medisinske fakultet \\ Universitet i Oslo

\section{Babak Irandoust} \\ Senter for sykelig overvekt \\ Oslo universitetssykehus, Aker

\section{Kåre I. Birkeland} \\ Avdeling for klinisk endokrinologi \\ Oslo universitetssykehus, Aker \\ og \\ Det medisinske fakultet \\ Universitetet i Oslo \\ Erlend T. Aasheim \\ Hormonlaboratoriet \\ Oslo universitetssykehus, Aker

\section{Carl Fredrik Schou \\ Jon Kristinsson} \\ Tom Mala \\ Senter for sykelig overvekt \\ og \\ Gastroenterologisk kirurgisk avdeling \\ Oslo universitetssykehus, Aker
}

Prevalensen av fedme har økt i Norge de siste tiårene (1). Overvekt og fedme disponerer for type 2-diabetes. Minst 100000 personer i Norge har kjent type 2-diabetes, men den reelle forekomsten er trolig langt høyere $(2,3)$. Type 2-diabetes øker risikoen for mikro- og makrovaskulære hendelser samt død forårsaket av iskemisk karsykdom (4). Intensiv medisinsk behandling for å senke blodsukkernivået hos pasienter med type 2diabetes reduserer forekomsten av mikrovaskulære komplikasjoner sammenliknet med mindre intens blodsukkerbehandling (5). Intensiv glykemisk kontroll reduserer også forekomsten av kardiovaskulære hendelser uten å være ledsaget av økt mortalitet, men sikkerheten ved slik behandling har vært diskutert $(6,7)$. Livsstilsintervensjon ved type 2-diabetes kan gi noe bedret blodsukkerkontroll, men fører i liten grad til varig vektreduksjon $(8,9)$.

En stor andel av pasienter med fedme har metabolsk syndrom, definert ved kriterier for metabolske risikofaktorer (10). Tilstedeværelse av metabolsk syndrom er forbundet med forhøyet risiko for type 2-diabetes og aterosklerotisk kardiovaskulær sykdom, samt økt total og kardiovaskulær dødelighet $(11,12)$. I en studie viste man at over $90 \%$ av pasientene med metabolsk syndrom ikke tilfredsstilte disse kriteriene ett år etter fedmekirurgi. De fleste pasientene var operert med vertikal innsnørt gastroplastikk (13).

Bariatrisk kirurgi fører til normalisering av blodsukkernivået ved type 2-diabetes for mange pasienter med sykelig fedme (14). I en metaanalyse hadde $78 \%$ av pasientene med type 2-diabetes før operasjon ikke diabetes ved oppfølging. Behandlingseffekten er relatert til hvilken kirurgisk prosedyre som er benyttet (15).

Kirurgisk behandling av sykelig fedme er et etablert behandlingstilbud i Norge (16). Ved Oslo universitetssykehus, Aker er det de siste to årene utført ca. 250 slike inngrep årlig, hvorav de fleste er laparoskopisk gastrisk bypass $(17,18)$. I denne studien evaluerte vi forekomsten av type 2-diabetes og metabolsk syndrom hos pasienter med sykelig fedme før og etter gastrisk bypass.

\section{Materiale og metode}

Studien ble utført som en retrospektiv analyse av prospektivt innsamlede pasientopplysninger. Data ble lagret i en database opprettet med konsesjon fra Datatilsynet, og skriftlig pasientsamtykke ble innhentet.

Indikasjon for operasjon var sykelig fedme, definert som BMI over $40 \mathrm{~kg} / \mathrm{m}^{2}$ eller over $35 \mathrm{~kg} / \mathrm{m}^{2}$ med vektrelatert tilleggssykdom (18). Pasienter operert med gastrisk bypass ved Oslo universitetssykehus, Aker i perioden 1.1. 2007-31.12. 2007, og med oppfølgingsdata mer enn seks måneder etter operasjon, ble inkludert i studien (fig 1).

Operasjonsteknikken er tidligere beskrevet i Tidsskriftet (18). Laparoskopisk tilgang ble benyttet. Opplysninger om tilleggssykdommer ble registrert fra henvisningsskriv og ved første konsultasjon på poliklinikken. Klinisk undersøkelse og blodprøveanalyse som dannet grunnlag for preoperativ vurdering av pasientene ble utført flere måneder før operasjon. Pasientene fikk individuell

\section{Hovedbudskap}

- Gastrisk bypass normaliserer blodsukkernivået hos de fleste pasientene med type 2-diabetes

- Forekomsten av metabolsk syndrom er betydelig lavere etter operasjon

- Lengre oppfølgingstid vil avklare om behandlingseffekten vedvarer 


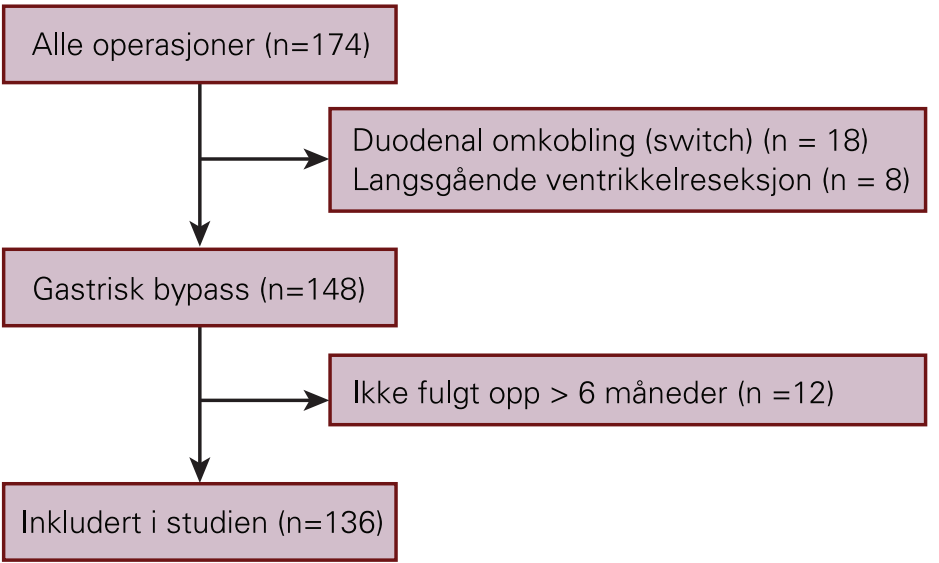

Figur 1 Fedmekirurgiske operasjoner ved Oslo universitetssykehus, Aker i 2007

kostholdsveiledning og ble anbefalt lavkaloridiett (4 $184 \mathrm{~J}$ (1 $000 \mathrm{kcal}) / \mathrm{dag})$ i tre uker før inngrepet. Etter operasjon fikk pasientene flytende kost $i$ en uke, moset mat $i$ to uker og deretter gradvis normal kost. Pasientene ble kontrollert av klinisk ernæringsfysiolog, kirurg eller indremedisiner etter seks uker, seks måneder samt ett og to år etter operasjon. Ved kontroller etter ett og to år ble komorbiditet og medikasjon registrert av lege. Blodtrykket ble målt ved slutten av konsultasjonen med pasienten sittende, ved bruk av automatisk blodtrykksapparat og bred mansjett. Data fra siste kontroll ble analysert.

\section{Definisjon av type 2-diabetes}

Preoperativt ble det tatt fastende blodprøver som ble analysert med standardmetoder ved Sentrallaboratoriet og Hormonlaboratoriet ved Oslo universitetssykehus, Aker. Etter operasjon ble det tatt blodprøver ved samme laboratorium, ved lokalsykehus eller hos fastlege. Før operasjon ble type 2-diabetes defi-

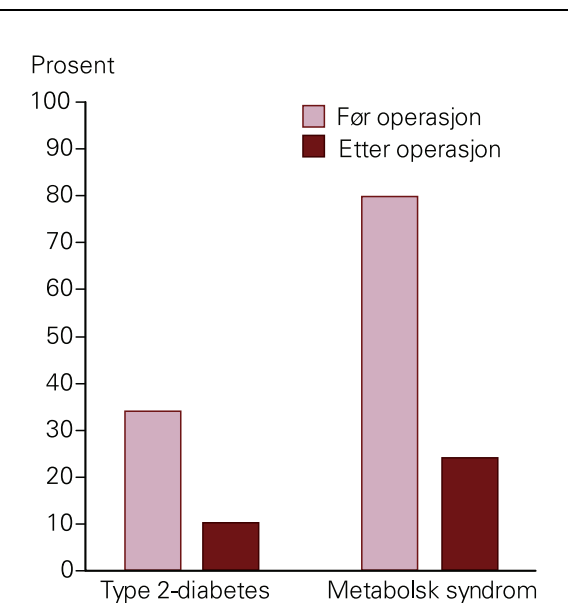

Figur 2 Forekomst av type 2-diabetes og metabolsk syndrom før og etter gjennomsnittlig 17 måneders oppfølgingstid etter gastrisk bypass nert som tilstedeværelse av minst ett av følgende kriterier: kjent type 2-diabetes ved henvisning eller journalopptak, fastende plasmaglukose $\geq 7,0 \mathrm{mmol} / \mathrm{l}$ eller $\mathrm{HbA}_{\mathrm{cc}} \geq 6,5 \%$. Remisjon av sykdommen ble definert som fastende plasma-glukose $<7,0 \mathrm{mmol} / \mathrm{l}$ og $\mathrm{HbA}_{1 \mathrm{c}}<6,5 \%$, uten bruk av antidiabetika. En pasient hadde kjent type 1-diabetes og ble ekskludert fra analyse vedrørende forekomsten av diabetes. Fastende C-peptid ble benyttet som mål på insulinresistens.

\section{Definisjon av metabolsk syndrom}

Før og etter operasjon ble pasientene undersøkt med tanke på forekomsten av metabolsk syndrom. Vi brukte den modifiserte definisjonen av metabolsk syndrom fra National Cholesterol Education Program (NCEP) Expert Panel (11). Syndromet defineres som tilstedeværelse av minst tre av fem av følgende kriterier: økt livvidde ( $\geq 102 \mathrm{~cm}$ for menn og $\geq 88 \mathrm{~cm}$ for kvinner), forhøyet nivå av triglyserider $(\geq 1,7 \mathrm{mmol} / \mathrm{l})$, lav HDL (high density lipoprotein $<1,03$ $\mathrm{mmol} / 1$ for menn og $<1,3 \mathrm{mmol} / 1$ for kvinner), høyt blodtrykk ( $\geq 130 \mathrm{~mm} \mathrm{Hg}$ systolisk eller $\geq 85 \mathrm{~mm} \mathrm{Hg}$ diastolisk) eller høy fastende plasma-glukose $(\geq 5,6 \mathrm{mmol} / \mathrm{l})$. $\mathrm{Pa}$ rede data for å kunne evaluere metabolsk syndrom før og etter operasjon forelå hos 122 av 136 pasienter.

\section{Statistikk}

Normalfordelte kontinuerlige data er angitt som gjennomsnittsverdi med standardavvik (SD) eller spredning. Ikke-normalfordelte data er angitt som median verdi med interkvartil spredning. Paret t-test og ikke-parametrisk analyse (Wilcoxons signed-rank test) ble brukt for å sammenlikne henholdsvis normalfordelte og ikke-normalfordelte kontinuerlige parede data. Parede kategoriske observasjoner ble sammenliknet med McNemars test. En tosidig p-verdi $<0,05$ ble ansett som statistisk signifikant. Beregningene ble gjort med SPSS versjon 15.0 for
Windows (SPSS Inc., Chicago, Illinois, USA).

\section{Resultater}

Totalt 174 fedmekirurgiske inngrep ble utført i 2007, hvorav 148 (85\%) var av typen gastrisk bypass. Av disse 148 pasientene hadde 136 pasienter oppfølgingsdata mer enn seks måneder etter operasjon og ble derfor inkludert i studien. $\mathrm{Ni}$ av de 12 pasientene som ble ekskludert møtte kun til kontroll etter seks uker eller seks måneder etter operasjon, to pasienter hadde flyttet utenlands og en pasient fra en annen helseregion ble ikke fulgt ved vår poliklinikk. Oppfølgingsdata registrert av lege ved sykehuset forelå hos 131 av de inkluderte pasientene. For fem pasienter ble data innhentet fra fastlege. Gjennomsnittlig oppfølgingstid var 17 måneder (spredning 8-26 md.).

Gjennomsnittsalder var $43 \pm 9$ år, 108 pasienter $(79 \%)$ var kvinner og ni $(7 \%)$ hadde ikke-vestlig etnisk bakgrunn. Gjennomsnittsvekt var $137 \pm 24 \mathrm{~kg}$ før operasjon og $94 \pm 20$ $\mathrm{kg}$ ved oppfølging etter operasjon ( $\mathrm{p}<0,001)$. Dette tilsvarer en gjennomsnittlig vektreduksjon på $31 \pm 8 \%$. Gjennomsnittlig kroppsmasseindeks var $47 \pm 6 \mathrm{~kg} / \mathrm{m}^{2}$ før og $32 \pm 6$ $\mathrm{kg} / \mathrm{m}^{2}$ etter operasjon $(\mathrm{p}<0,001)$. Det var ingen nytilkomne tilfeller av type 2-diabetes eller metabolsk syndrom i oppfølgingsperioden.

\section{Type 2-diabetes}

Andel av pasientene som hadde type 2-diabetes var 46/136 (34\%) før operasjon og 13/ 136 pasienter $(10 \%)$ etter $(\mathrm{p}<0,001$, fig 2$)$. Tabell 1 viser endringer i kliniske og laboratoriemessige variabler for disse pasientene. Totalt oppfylte $33 / 46$ pasienter $(72 \%)$ med type 2-diabetes før operasjon ikke lenger definisjonen for denne diagnosen etter operasjon. Gjennomsnittlig eller median verdi for fastende plasma-glukose, $\mathrm{HbA}_{1 \mathrm{c}}$ og C-peptid var alle lavere hos disse 46 pasientene etter operasjon. Andel av pasientene med type 2-diabetes som brukte antidiabetisk medikasjon før operasjon, var 34/46 pasienter (74\%), hvorav 12 ble behandlet med insulin. Tilsvarende tall etter operasjon var 9/13 $(69 \%)$, hvorav fem brukte insulin.

\section{Metabolsk syndrom}

Kriteriene for metabolsk syndrom var oppfylt hos $98 / 122$ pasienter ( $80 \%$ ) før operasjon og 29/122 (24\%) etter ( $p<0,001$, fig 2$)$. Det var bedring i gjennomsnittlig eller median verdi for alle komponentene som inngår i NCEPs definisjon av metabolsk syndrom (tab 2). Av de 98 pasientene som oppfylte kriteriene for metabolsk syndrom før inngrepet, brukte 20/98 (20\%) lipidsenkende behandling før operasjon og 4/98 (4\%) etter $(\mathrm{p}<0,001)$. Tilsvarende tall for antihypertensiv behandling var henholdsvis $35 / 98$ $(36 \%)$ og 16/98 (16\%); og for antidiabetisk medikasjon 30/98 (31\%) før og 7/98 (7\%) etter operasjon ( $p<0,001$ for begge). 
For pasienter med type 2-diabetes før operasjon, hadde 43 av 46 pasienter parede data for å evaluere metabolsk syndrom før og etter operasjon. Kriteriene for metabolsk syndrom var oppfylt hos 41/43 pasienter (95\%) før operasjon og 19/43 (44\%) etter $(\mathrm{p}<0,001)$.

\section{Diskusjon}

I denne studien førte gastrisk bypass for sykelig fedme til normalisering av plasma-glukosenivået hos $72 \%$ av pasientene med type 2-diabetes. Dette er i samsvar med internasjonale data, som også viser at behandlingseffekten kan variere avhengig av hvor lenge pasientene har hatt type 2-diabetes, hvordan diagnosen stilles og oppfølgingstid. I en metaanalyse er det vist at type 2-diabetes gikk i remisjon hos $80 \%$ av pasientene etter gastrisk bypass (15).

For pasienter med type 2-diabetes inntrer den blodsukkersenkende effekten av gastrisk bypass raskt. Mange kan seponere antidiabetisk medikasjon etter få dager. En av teoriene for dette er at eksklusjon av fødemidler fra proksimale tynntarm, som følge av omkobling av tarmsegmenter, medfører bedret glukosetoleranse (19). Etter operasjonen øker måltidsstimulert frigjøring av gastrointestinale peptider (for eksempel inkretinet glukagonliknende peptid-1). Dette er assosiert med økt insulinsekresjon fra betacellene i pancreas og redusert matinntak. Over tid vil vektreduksjon i seg selv føre til bedret insulinfølsomhet og redusert insulinbehov. Langtidsdata for den blodsukkersenkende effekten av gastrisk bypass ved type 2-diabetes er fremdeles lite studert, men enkelte rapporter tyder på at den vedvarer (20). For en del pasienter vil trolig økende alder og vekt igjen føre til høyere blodsukkerverdier (21). Det er uklart hvor mye man skal vektlegge tilstedeværelse av type 2-diabetes i prioriteringen av pasienter med sykelig fedme for kirurgisk behandling.

Andel av pasientene med metabolsk syndrom var betydelig lavere etter gastrisk bypass. Dette samsvarer med funn i andre studier, som i tillegg har demonstrert signifikant lavere forekomst av metabolsk syndrom allerede få uker etter operasjon $(13,22)$. Definisjonen av metabolsk syndrom er et hjelpemiddel for å identifisere pasienter med særlig risiko for type 2-diabetes og aterosklerotisk kardiovaskulær sykdom (11). Livsstilsråd som økt fysisk aktivitet, kostholdsendring og røykeslutt er sentrale for denne pasientgruppen. Våre resultater viser at pasientene oppnår stor vektreduksjon og signifikante bedringer av kardiovaskulære risikofaktorer etter gastrisk bypass.

En svakhet ved studien er at pasientene ikke fikk utført peroral glukosebelastning. Denne undersøkelsen kunne avdekket flere pasienter med type 2-diabetes både før og etter operasjon. Ikke alle laboratoriemålinger ble gjort ved samme laboratorium, men siden standardiserte analysemetoder ble benyttet,

Tabell 1 Vekt, kroppsmasseindeks og mål for glukosehomøostase før og $18 \pm 4$ måneder etter gastrisk bypass hos 46 pasienter med type 2-diabetes før operasjon. Referanseintervaller ved Oslo universitetssykehus, Aker: fastende plasma-glukose 4,0-6,0 mmol/l; $\mathrm{HbA}{ }_{1 c} 4,0-6,0 \%$; fastende C-peptid 220-1 $400 \mathrm{pmol} / \mathrm{l}$

\begin{tabular}{|c|c|c|c|}
\hline & Før operasjon & Etter operasjon & P-verdi \\
\hline Vekt $(\mathrm{kg})^{1}$ & $139 \pm 25$ & $98 \pm 23$ & $<0,001$ \\
\hline BMI $\left(\mathrm{kg} / \mathrm{m}^{2}\right)^{1}$ & $47 \pm 6$ & $33 \pm 6$ & $<0,001$ \\
\hline Fastende plasma-glukose $(\mathrm{mmol} / \mathrm{l})^{2}$ & $7,0(6,1-9,0)$ & $5,3(5,0-6,1)$ & $<0,001$ \\
\hline $\mathrm{HbA}_{1 \mathrm{c}}(\%)^{2}$ & $7,1(6,5-8,5)$ & $5,6(5,4-5,9)$ & $<0,001$ \\
\hline Fastende C-peptid $(p m o l /)^{2}$ & $1383(1053-1781)$ & $822(579-1112)$ & $<0,001$ \\
\hline
\end{tabular}

1 Gjennomsnittsverdi med standardavvik

2 Median verdi med interkvartil spredning

Tabell 2 Komponenter av metabolsk syndrom-kriterier fra National Cholesterol Education Program (11) - før og $17 \pm 4$ måneder etter gastrisk bypass hos 98 pasienter med metabolsk syndrom før operasjon

\begin{tabular}{|c|c|c|c|c|c|}
\hline Kriterium & Enhet & Grenseverdi & Før operasjon & Etter operasjon & P-verdi \\
\hline \multicolumn{6}{|l|}{ Livvidde $^{1}$} \\
\hline Menn & $\mathrm{cm}$ & $\geq 102$ & $151 \pm 12$ & $119 \pm 19$ & $<0,001$ \\
\hline Kvinner & $\mathrm{cm}$ & $\geq 88$ & $136 \pm 14$ & $103 \pm 14$ & $<0,001$ \\
\hline Triglyserider ${ }^{2}$ & $\mathrm{mmol} / \mathrm{l}$ & $\geq 1,7$ & $1,7(1,2-2,3)$ & $1,0(0,8-1,3)$ & $<0,001$ \\
\hline \multicolumn{6}{|l|}{$\mathrm{HDL}^{2}$} \\
\hline Menn & $\mathrm{mmol} / \mathrm{l}$ & $<1,03$ & $0,96(0,90-1,26)$ & $1,20(1,10-1,51)$ & $<0,001$ \\
\hline Kvinner & $\mathrm{mmol} / \mathrm{l}$ & $<1,3$ & $1,2(1,0-1,4)$ & $1,4(1,2-1,7)$ & $<0,001$ \\
\hline Systolisk blodtrykk ${ }^{1}$ & $\mathrm{~mm} \mathrm{Hg}$ & $\geq 130^{3}$ & $142 \pm 16$ & $129 \pm 15$ & $<0,001$ \\
\hline Diastolisk blodtrykk & $\mathrm{mm} \mathrm{Hg}$ & $\geq 85^{3}$ & $89 \pm 12$ & $80 \pm 11$ & $<0,001$ \\
\hline Fastende glukose ${ }^{2}$ & $\mathrm{mmol} / \mathrm{l}$ & $\geq 5,6^{4}$ & $6,1(5,5-6,7)$ & $5,1(4,8-5,5)$ & $<0,001$ \\
\hline
\end{tabular}

1 Gjennomsnittsverdi med standardavvik

${ }_{2}^{2}$ Median verdi med interkvartil spredning

${ }^{3}$ Eller medikamentell hypertensjonsbehandling

${ }_{4}$ Eller type 2-diabetes

har dette trolig liten betydning. Oppfølgingstiden var gjennomsnittlig 17 måneder. Noen pasienter med kort oppfølgingstid vil ikke ha oppnådd maksimalt vekttap, som vanligvis oppnås 1-2 år postoperativt. Ytterligere vektreduksjon hos enkelte pasienter kunne ha vært av betydning for resultatene i studien.

Vi takker Inger Eribe og Ann Steen ved Overvekts poliklinikken for hjelp med registrering av data.

Oppgitte interessekonflikter: Ingen

\section{Litteratur}

1. Ulset E, Undheim R, Malterud K. Er fedmeepide mien kommet til Norge? Tidsskr Nor Lægeforen 2007; 127: $34-7$.

2. Midthjell K, Krüger 0, Holmen J et al. Rapid changes in the prevalence of obesity and known diabetes in an adult Norwegian population. The Nord Trondelag Health Surveys: 1984-1986 and 1995-1997. Diabetes Care 1999; 22: 1813-20.

3. Stene LC, Midthjell K, Jenum AK et al. Hvor mange har diabetes mellitus i Norge? Tidsskr Nor Lægeforen 2004; 124: 1511-4

4. Dale AC, Nilsen TI, Vatten L et al. Diabetes mellitus and risk of fatal ischaemic heart disease by gender: 18 years follow-up of 74.914 individuals in the HUNT 1 Study. Eur Heart J 2007; 28: 2924-9.

5. Patel A, MacMahon S, Chalmers J et al. Intensive blood glucose control and vascular outcomes in patients with type 2 diabetes. N Engl J Med 2008; 358: $2560-72$.
6. Ray KK, Seshasai SR, Wijesuriya S et al. Effect of intensive control of glucose on cardiovascular out comes and death in patients with diabetes mellitus: a meta-analysis of randomised controlled trials. Lancet 2009: 373: 1765-72.

7. Gerstein HC, Miller ME, Byington RP et al. Effects of intensive glucose lowering in type 2 diabetes. N Engl J Med 2008; 358: 2545-59.

8. Aas AM, Bergstad I, Thorsby PM et al. An intensified lifestyle intervention programme may be superior to insulin treatment in poorly controlled Type 2 diabetic patients on oral hypoglycaemic agents: results of a feasibility study. Diabet Med 2005; 22: 316-22.

9. Norris SL, Zhang X, Avenell A et al. Long-term non-pharmacologic weight loss interventions for adults with type 2 diabetes. Cochrane Database Syst Rev 2005; 2: CD004095.

10. Halvorsen LK, Tonstad S. Metabolsk syndrom hos pasienter med fedme. Tidsskr Nor Legeforen 2008; 128: 2305-7.

11. Grundy SM, Cleeman JI, Daniels SR et al. Diagnosis and management of the metabolic syndrome: an American Heart Association/National Heart Lung, and Blood Institute Scientific Statement. Circulation 2005; 112: 2735-52.

12. Sundström J, Riserus U, Byberg $L$ et al. Clinical value of the metabolic syndrome for long term prediction of total and cardiovascular mortality: prospective, population based cohort study. BMJ 2006; 332: 878-82.

13. Lee WJ, Huang MT, Wang W et al. Effects of obesity surgery on the metabolic syndrome. Arch Surg 2004; 139: 1088-92. 
14. Pories WJ, MacDonald KG jr., Morgan EJ et al. Surgical treatment of obesity and its effect on diabetes: 10-y follow-up. Am J Clin Nutr 1992; 55 I2 suppl): $582-5$

15. Buchwald H, Estok R, Fahrbach K et al. Weight and type 2 diabetes after bariatric surgery: systematic review and meta-analysis. Am J Med 2009; 122: 248-56.

16. Aasheim ET, Mala T, Søvik TT et al. Kirurgisk behandling av sykelig fedme. Tidsskr Nor Lægeforen 2007; 127: 38-42.

17. Søvik TT, Aasheim ET, Kristinsson J et al. Establishing laparoscopic Roux-en-Y gastric bypass: perioperative outcome and characteristics of the learning curve. Obes Surg 2009; 19: 158-65.

18. Søvik TT, Aasheim ET, Kristinsson J et al. Laparoskopisk kirurgi ved sykelig fedme ved et regionalt senter. Tidsskr Nor Lægeforen 2007; 127: 47-9.

19. Thaler JP, Cummings DE. Minireview: hormonal and metabolic mechanisms of diabetes remission after gastrointestinal surgery. Endocrinology 2009 150: $2518-25$

20. Pories WJ, Swanson MS, MacDonald KG et al. Who would have thought it? An operation proves to be the most effective therapy for adult-onset diabetes mellitus. Ann Surg 1995; 222: 339-50.

21. Sjöström L, Lindroos AK, Peltonen $M$ et al. Lifestyle, diabetes, and cardiovascular risk factors 10 years after bariatric surgery. N Engl J Med 2004; 351: $2683-93$.

22. Morinigo R, Casamitjana R, Delgado $S$ et al. Insulin resistance, inflammation, and the metabolic syndrome following Roux-en-Y gastric bypass surgery in severely obese subjects. Diabetes Care 2007; 30 : 1906-8.

Manuskriptet ble mottatt 6.8. 2009 og godkjent

15.4. 2010. Medisinsk redaktør Åslaug Helland. 